\title{
Garantir a cidadania das mulheres: A indiferença e outros obstáculos
}

Securing Women's Citizenship: Indifference and Other Obstacles

Garantir la citoyenneté des femmes : l'indifférence et autres obstacles

\section{Carole Pateman}

Tradutor: Teresa Tavares

\section{(2) OpenEdition}

\section{Journals}

Edição electrónica

URL: http://journals.openedition.org/rccs/3666

DOI: $10.4000 /$ rccs.3666

ISSN: $2182-7435$

Editora

Centro de Estudos Sociais da Universidade de Coimbra

\section{Edição impressa}

Data de publição: 1 Junho 2010

Paginação: $29-40$

ISSN: 0254-1106

\section{Refêrencia eletrónica}

Carole Pateman, «Garantir a cidadania das mulheres: A indiferença e outros obstáculos », Revista Crítica de Ciências Sociais [Online], 89 | 2010, colocado online no dia 01 outubro 2012, criado a 30 abril 2019. URL : http://journals.openedition.org/rccs/3666 ; DOI : 10.4000/rccs.3666

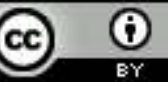




\title{
CAROLE PATEMAN
}

\section{Garantir a cidadania das mulheres: A indiferença e outros obstáculos}

\begin{abstract}
Este artigo discute as estruturas sexuais e raciais de poder que continuam a obstruir de forma sistemática a cidadania das mulheres. As reformas jurídicas e políticas concretizadas em muitos países não foram acompanhadas por mudanças correspondentes nas práticas sociais de dominação e subordinação e nas concepções de masculinidade e feminilidade. A este obstáculo junta-se a pobreza, que afecta maioritariamente as mulheres a nível global, e o crescimento da desigualdade induzido pela redução, privatização e eliminação de serviços públicos, que têm levado ao acréscimo do fardo quotidiano das mulheres, especialmente nos países pobres. O empobrecimento das mulheres e as guerras das duas últimas décadas têm fomentado o tráfico sexual global e a violência contra as mulheres. A indiferença relativamente a estes fenómenos tem por base (e reforça) o contrato sexual-racial global. De forma a eliminar a interacção entre o contrato de indiferença mútua e o contrato sexual-racial global, propõe-se que a atribuição de um rendimento básico a todos os cidadãos constituiria um passo em direcção a uma cidadania plena.
\end{abstract}

Palavras-chave: cidadania; crimes contra as mulheres; direitos; discriminação étnico-racial; pobreza; discriminação sexual; rendimento básico.

Se olharmos para o século que passou, constatamos que houve muitas melhorias na posição social e económica das mulheres e na sua situação política, jurídica e cívica desde 1908. Contudo, justifica-se ainda levantar a questão: serão as mulheres hoje cidadãs de pleno direito em todos os países do mundo?

A resposta a esta pergunta depende, evidentemente, do que entendemos por "cidadania plena". O sufrágio é o símbolo primeiro da cidadania e, se for tomado como medida, o contraste com 1908 torna-se muito evidente. Há um século, as mulheres apenas participavam em três eleitorados nacionais: na Nova Zelândia, Austrália e Finlândia. Em 2008, o direito ao voto é quase universal - a grande maioria das mulheres e dos homens participam agora nas eleições dos seus países -, sendo a Arábia Saudita ainda uma excepção a assinalar. 
Contudo, o direito ao voto, embora importante e necessário, constitui apenas uma parte da cidadania. Outros direitos políticos e jurídicos são indispensáveis. Para que a cidadania seja algo mais do que formal, para que tenha um efeito significativo na vida quotidiana e igual valor para todos/as os/as cidadãos/ãs, cada indivíduo tem de ser aceite em pé de igualdade como participante em todas as áreas da vida política e social. Todos/as os/as cidadãs/ãos devem ser considerados/as e aceites como membros iguais das suas sociedades num sentido substantivo e não meramente formal. Pode argumentar-se que a cidadania não é apenas um problema para as mulheres; também nem todos os homens são membros plenos e iguais das suas sociedades. Os homens pobres e os que pertencem a uma variedade de grupos raciais e étnicos são empurrados para as margens ou perseguidos em muitos países do mundo. Mas as mulheres confrontam-se com alguns problemas muito específicos no que se refere à cidadania, embora algumas das questões que discutirei também sejam relevantes para os homens.

O contraste com 1908 não é assim tão dramático se considerarmos outros aspectos da cidadania para além do sufrágio. Ainda persistem muitos dos problemas que existiam há um século, embora num contexto muito diferente. Por todo o mundo, as mulheres ainda enfrentam numerosas dificuldades em garantir plenamente o estatuto de cidadãs. Alguns problemas são mais prevalecentes ou mais graves em certos países e áreas; outros verificam-se a nível global, mas a forma que assumem difere de acordo com os contextos e as culturas. Há mais de uma década, as Nações Unidas alargaram o âmbito dos seus estudos de desenvolvimento humano, passando a incluir um Índice de Desenvolvimento Relativo ao Género e uma Medida de Capacitação de Género. Tal foi necessário devido à amplitude da desigualdade entre mulheres e homens e ao grau de marginalização e exclusão das mulheres da vida política e económica; por outras palavras, os índices de género são necessários devido à posição inferior das mulheres em termos sociais, políticos e económicos. Colocando a questão de modo diferente, as estruturas sexuais e raciais de poder obstruem de forma sistemática a cidadania formal das mulheres.

Mas por que é que a cidadania das mulheres tem revelado ser um tal problema? Não há nenhuma resposta simples para explicar por que razão os obstáculos são tão difíceis de ultrapassar. Tem sido mais fácil concretizar reformas jurídicas e políticas - embora ainda haja um longo caminho a percorrer em termos globais - do que mudanças nas práticas sociais, nas crenças e atitudes e nas concepções de masculinidade e feminilidade. Mas isto não é grande surpresa, pois o que está em causa são questões de poder e privilégio, de dominação e subordinação. Quem tem poder jamais deseja 
ceder a sua posição, especialmente quando, como no caso do poder masculino, se estende à vida quotidiana e familiar e às áreas mais íntimas da individualidade, permitindo que cada homem tenha uma parcela, por muito pequena que seja, dos privilégios da masculinidade.

Para ilustrar o problema, consideremos o direito de voto, esse símbolo da cidadania, bem como o direito a ser eleito. Hoje em dia, o sufrágio universal é visto como necessário para a formação de um governo legítimo, mas esquece-se a longuíssima luta que foi preciso travar para obter o voto para todos os cidadãos. Nos Estados Unidos e na Grã-Bretanha, por exemplo, foram precisos 60 anos de campanhas contínuas, em face de profunda hostilidade e por vezes violência, para que todas as mulheres obtivessem o direito de voto, e nos Estados Unidos só foi depois das reformas que começaram na década de 1960 que todas as mulheres afro-americanas e todos os homens afro-americanos conseguiram exercer livremente o seu direito de voto. Em vários países europeus, nem todas as mulheres tinham esse direito até à década de 1970, e num dos cantões suíços essa situação manteve-se até ao final da década de 1980.

Mas se o sufrágio é em geral incontroverso, já o mesmo não pode dizer-se relativamente à eleição de mulheres para cargos públicos e à sua participação em órgãos de decisão. As deputadas da Câmara dos Comuns do Parlamento do Reino Unido têm constatado que os deputados ainda as vêem com hostilidade ou como uma anedota (sexista). Os números reportados pela União Interparlamentar [Inter-Parliamentary Union] relativamente a Novembro de 2007 mostram que a percentagem média de mulheres nas legislaturas de todo o mundo era ainda só $17,2 \%$, mas há uma grande variação de país para país (consultar http://www.ipu.org). Em câmaras baixas ou únicas, a região nórdica tem $41,8 \%$ de mulheres, mas o Ruanda tem a percentagem mais elevada em termos de países individuais, com $48,8 \%$. A posição de muitos países ricos é bastante inferior à dos mais pobres: por exemplo, Moçambique tem 34,8\% de mulheres, o Peru 29,2\%, enquanto Portugal tem apenas $21,3 \%$, o Reino Unido $19,7 \%$ e os EUA $16,3 \%$. As mulheres têm geralmente uma representação maior em câmaras municipais e órgãos semelhantes, mas este facto tem-se verificado desde o século XIX. A tomada de decisões a nível local é mais facilmente vista como um campo apropriado para a aç̧ão das mulheres do que a arena nacional.

Nos últimos anos, mais mulheres têm ocupado cargos executivos; em Espanha, elas constituem agora a maioria dos membros do conselho de ministros e há mesmo uma ministra da defesa grávida. As mulheres têm cumprido funções de primeiro-ministro e de presidente desde a década de 1960, mas os homens ainda monopolizam as posições de autoridade, quer 
seja nas legislaturas ou nos governos (quando se fazem fotografias, a imagem é tipicamente de homens estadistas), quer seja nas instituições económicas, militares e judiciais ou nas universidades.

Os países nórdicos tomaram medidas especiais para conseguir uma representação adequada de mulheres nas legislaturas e no governo e, mais ou menos na última década, mais de cem países adoptaram variadas formas de quotas para a selecção de candidatas a cargos públicos. A Noruega agora empenhou também os seus esforços noutro domínio. Uma lei promulgada em 2003 determinou que as companhias públicas limitadas deveriam ter $40 \%$ de mulheres nos conselhos de administração até 1 de Janeiro de 2008. Um quarto delas não conseguiu fazê-lo (5 não nomearam sequer uma mulher), mas a Noruega hoje tem a proporção mais alta do mundo de mulheres em conselhos de administração de empresas, 37\% (os EUA têm cerca de $15 \%$ ).

Poderíamos continuar a dar exemplos da sub-representação das mulheres, mas a questão geral é que os homens continuam a ser vistos como figuras de maior autoridade do que as mulheres. A palavra dos homens vale mais do que a das mulheres, o que é um obstáculo à cidadania plena das mulheres e um aspecto das ramificações mais vastas das crenças acerca da masculinidade e da feminilidade que discuti no meu livro The Sexual Contract (1988). Apesar das muitas mudanças ocorridas nas últimas décadas, os rapazinhos e os homens valem mais do que as meninas e as mulheres. Podemos encontrar o exemplo mais evidente das consequências da conviç̧ão profunda de que os seres humanos machos valem mais do que as fêmeas em certas áreas do mundo, na China, por exemplo, onde há uma preferência extremamente forte por rapazes. $\mathrm{O}$ aborto selectivo, o infanticídio e a negligência em geral resultaram num grande desequilíbrio a favor dos homens. O relato mais conhecido deste fenómeno é o de Amartya Sen (1990: 61-66), que em 1990 estimou que este desequilíbrio seria de mais de 100 milhões de mulheres a nível mundial.

Regressarei ao problema de quem vale mais. Por agora, gostaria de falar acerca de outro obstáculo à cidadania das mulheres - a pobreza. No último quartel, houve um aumento marcante da desigualdade económica e da insegurança, tanto dentro de cada país como entre o Norte global e o Sul global. Este aumento tem sido induzido pelas doutrinas neoliberais de ajustamento estrutural, desregulação e privatização, doutrinas essas que subjazem a muitas das grandes mudanças que agora se agrupam sob a designação de "globalização." O Relatório de Desenvolvimento Humano de 2005 das Nações Unidas dá-nos um resumo da amplitude da desigualdade global. Apesar de algumas melhorias em áreas como o analfabetismo e as doenças curáveis, 
as desigualdades de rendimento aumentaram nos países onde vive $80 \%$ da população mundial. Dois mil milhões e meio de pessoas vivem com menos de $\$ 2$ por dia e mais de mil milhões com menos de $\$ 1$ por dia. Os $10 \%$ mais ricos detêm 54\% do rendimento global (http://hdr.undp.org/en/reports/ global/hdr2005/).

A pobreza constitui um problema para a cidadania tanto dos homens como das mulheres, mas estas tendem a estar entre os mais pobres dos pobres. A pobreza está correlacionada com a subnutrição, a falta de saúde e de educação e a marginalização social em geral. E, em 2008, com a subida rápida do preço dos alimentos a nível global, o sofrimento dos pobres aumentará. Não é fácil ser-se saudável se se fizer parte dos mil milhões de pessoas que não têm acesso a água potável ou dos 2,6 mil milhões que não têm acesso a saneamento básico. Quanto é que vale a cidadania se as pessoas estão permanentemente debilitadas, com fome e têm de trabalhar infindavelmente apenas para subsistir? As mulheres dos países pobres têm problemas ainda mais específicos: por exemplo, mais de meio milhão delas morrem anualmente de parto; as mulheres e raparigas passam frequentemente muitas horas por dia a buscar água e lenha; em alguns países, não podem herdar terras; têm mais probabilidades de ser analfabetas do que os homens; e os campos de refugiados e deslocados estão cheios de mulheres e crianças. Um dos factores da crescente desigualdade é a redução, privatização e eliminação de serviços públicos, que levaram ao acréscimo dos fardos quotidianos das mulheres, especialmente nos países pobres.

Os milhões de mulheres que se encontram em situação de extrema pobreza e destituição vivem maioritariamente em países pobres não-brancos, mas as desigualdades também têm aumentado dentro dos países ricos. Por exemplo, se os EUA usassem a definição comum de pobreza - viver com $60 \%$ do salário médio -, 23,8\% da sua população estaria a viver em condições de pobreza em 2000. Nos países ricos, as mulheres e os homens não-brancos encontram-se em proporções excessivas nos escalões dos pobres. As mulheres continuam a ganhar menos que os homens e tendem a concentrar-se nos sectores mais baixos da estrutura de emprego em termos de remuneração e estatuto. Os seus padrões de carreira, bem como o legado do velho modelo do provedor masculino do Estado-Providência, implicam que têm geralmente menos meios de subsistência na velhice do que os homens. Neste sentido material, a cidadania das mulheres não tem o mesmo valor que a dos homens.

Para além disso, embora a maioria das mulheres nos países brancos ricos esteja agora no mercado de trabalho, continuam a ser elas normalmente as responsáveis pelo trabalho doméstico e de prestação de cuidados. 
Os homens aproveitam-se desta situação e recusam-se a fazer a parte que lhes cabe. Um estudo recente envolvendo 28 países revelou que os homens fazem em média 9,4 horas semanais de trabalho doméstico, ao passo que as mulheres fazem 21,13 horas (Dobson e Waite, 2007). Uma das consequências deste alijar do trabalho de prestação de cuidados por parte dos homens, conjugado com o desejo de evitar conflitos conjugais, é o reaparecimento das empregadas domésticas. Hoje em dia, a tendência crescente é para essas empregadas virem de países estrangeiros, incluindo países não-ocidentais, em vez de serem recrutadas entre a classe trabalhadora local: há agora "uma transferência global de serviços associados ao papel tradicional da esposa [...] dos países pobres para os ricos" (Ehrenreich e Hochschild, 2002: 4). Muitas mulheres pobres emigram para trabalhar como criadas e amas, enviando remessas para sustentar as suas famílias. Viajam do Sudeste da Ásia para o Médio ou Extremo Oriente, do ex-bloco soviético e de África para a Europa Ocidental, e do Sul para o Norte das Américas. Ser empregada ou ama significa (a não ser que a ama use uniforme e cuide das crianças dos muito ricos ou famosos) estar no fundo da mão-de-obra assalariada.

Este ressurgir do serviço doméstico ocorreu nos 20 anos que se passaram desde a publicação de The Sexual Contract. Neste livro, salientei que não era possível compreender o estatuto menor das mulheres como cidadãs sem se investigar o modo como está relacionado com a sua posição no lar e no local de trabalho, ambos também interligados. Há mais de 150 anos que o trabalho está intimamente ligado à cidadania, mas agora passou para uma fase diferente. Especialmente nos Estados Unidos e na Grã-Bretanha, o poder das doutrinas neoliberais e a mudança da previdência social para a previdência no trabalho (workfare) (o requisito de que os receptores entrem no mercado de trabalho para receberem subsídios) significam que o elo de ligação entre a cidadania e o "trabalho", isto é, o emprego remunerado, é agora mais forte do que nunca. O pressuposto é que todos os adultos capazes devem estar empregados; nos Estados Unidos, desde a reforma da previdência social em 1996, isto abrange inclusivamente as mães de crianças pequenas, o que constitui uma mudança histórica.

Estes desenvolvimentos sublinham o argumento que as feministas, entre as quais eu me incluo, há tanto tempo vêm defendendo: o de que o trabalho de prestação de cuidados não remunerado efectuado pelas mulheres nas suas casas não é visto como "trabalho" que "contribua" para a cidadania. É porque as mulheres fazem a maior parte deste trabalho que é difícil vê-las como cidadãs que dão o seu contributo da mesma forma que os homens. O seu trabalho não remunerado também afecta o seu contributo no emprego, tendendo elas muito mais do que os homens a trabalhar a tempo 
parcial (de forma a poderem continuar a desempenhar o trabalho doméstico). A prevalência do assédio sexual no local de trabalho e o número de processos de discriminação levados a tribunal por mulheres nos escalões profissionais mais elevados, como por exemplo na banca de investimento, indicam também que as mulheres não são ainda consideradas como participantes "públicas" da mesma forma que os homens.

No meu último livro, intitulado Contract and Domination (2007), escrito em colaboração com Charles Mills (autor de The Racial Contract), procurámos abordar a intersecção dos contratos sexual e racial, e eu usei o tráfico de empregadas domésticas como ilustração daquilo a que chamei o contrato sexual-racial global. Ao discutir este contrato mais lato, uso o termo "contrato" com um sentido diferente daquele que usei em The Sexual Contract, em que a minha argumentação se baseou na tradição das teorias clássicas da Idade Moderna relativas a um contrato original. No entanto, penso que o conceito de "contrato" dos teóricos clássicos não pode ser aplicado aos padrões globais de desigualdade. Assim, na minha análise do contrato sexual-racial global utilizo o termo num sentido metafórico, à semelhança da maioria dos actuais teóricos contratualistas.

À semelhança das teorias da Idade Moderna, defendo que o contrato sexual emerge da(s) (narrativas acerca da) criação e justificação de uma forma específica de ordem política, o estado constitucional moderno (nos termos dos teóricos clássicos, esta é a "sociedade civil" que substitui o "estado da natureza"). Também explorei o modo como certos contratos concretos, especialmente os contratos de matrimónio e de emprego, levaram à reprodução da subordinação das mulheres. Os teóricos clássicos têm muito a dizer acerca das instituições e da estrutura de poder da nova forma de sociedade política e interessaram-se por todo o tipo de questões, desde a masculinidade e feminilidade ao casamento, à propriedade privada e à forma de governo do estado.

Os teóricos clássicos são frequentemente invocados pelos teóricos contratualistas contemporâneos, mas o facto de os primeiros terem discutido as estruturas de poder das instituições, bem como o poder sexual e racial, tem gradualmente desaparecido da discussão. Ao invés, desde a publicação de A Theory of Justice de John Rawls (1971), o foco tem incidido sobre a razão moral e os princípios morais que escolheríamos se pensássemos racionalmente sobre a escolha. Por outras palavras, o contrato não funciona, como muitos dos envolvidos reconhecem, e a discussão poderia facilmente decorrer sem ele. O contrato tornou-se numa mera metáfora.

Também Charles Mills emprega o termo num sentido metafórico, embora eu deva sublinhar que ele modifica o quadro de Rawls de forma a realçar 
as estruturas de poder, e portanto usa o conceito com propósitos emancipatórios. Eu discordo dele relativamente à teoria contratualista e as nossas discordâncias são debatidas no nosso novo livro. Mas o "contrato" como metáfora ampla, como Mills mostra, pode ser útil para certos propósitos. Por exemplo, o termo "contrato sexual" é agora usado de forma bastante abrangente, embora tipicamente para salientar a asserção - uma asserção que discuti em The Sexual Contract e que está no centro dos problemas da cidadania das mulheres - de que a subordinação das mulheres aos homens se justifica, que os homens têm o direito de governar as mulheres. É a ubiquidade da subordinação das mulheres, manifestada numa multiplicidade de formas e com graus variados de intensidade, que permite às feministas usar o termo "contrato sexual" para captar este fenómeno.

No novo livro, também uso a ideia de um contrato de indiferença mútua, que fui buscar ao trabalho de Norman Geras (1998), o qual utiliza de igual modo o termo "contrato" em sentido metafórico. ${ }^{1}$ Ele argumenta que este contrato reflecte um mundo em que, em geral, as pessoas permanecem impassíveis perante atrocidades extremas e situações de grande privação e sofrimento. Geras não nega que há pessoas e grupos motivados pelo humanitarismo que se esforçam, por vezes de forma heróica, por ajudar os que sofrem, mas a maioria das pessoas, na maioria do tempo, não o fazem. Segundo Geras, o contrato reflecte relações gerais, mas não universais, de indiferença. É um modelo do mundo que ele diz ser "exagerado - ou, talvez mais exactamente, reduzido - por omissão dos casos que existem de comportamento de auxílio mútuo em situações da desgraça extrema" (1998: 29). O contrato assume a forma de um pacto: eu não te presto auxílio numa emergência e não espero que o prestes a mim. Regemo-nos pela indiferença mútua.

Como Geras nota, há muitas organizações e indivíduos que se dedicam a ajudar quem sofre - mas omite-se frequentemente o facto de que nem todos os casos são considerados como dignos da mesma atenção. Não é possível entender este fenómeno nem a indiferença sem tomar igualmente em conta os contratos sexual e racial ou, mais precisamente, o contrato sexual-racial global. A resposta e a ausência de resposta são refractadas pelos contratos sexual e racial.

Consideremos a indiferença que existiu durante um quarto de século às mortes e atrocidades em Timor Leste depois da sua invasão e anexação pela Indonésia. Consideremos a falta de interesse pelo destino de 4 milhões de pessoas que morreram nos últimos anos devido à guerra e às

\footnotetext{
${ }^{1}$ Os parágrafos que se seguem são retirados do capítulo 5 da obra Contract and Domination.
} 
suas consequências na República Democrática do Congo. Consideremos a questão dos direitos humanos e dos direitos das mulheres. Só depois das campanhas da década de 1990 é que os crimes contra as mulheres, cometidos não só pelo estado e por grupos armados, mas também pelos seus maridos e parentes, começaram a ser reconhecidos como violações de direitos bumanos. As mulheres sempre foram vistas como um dos espólios da guerra e a violação é usada em larga escala como uma arma de guerra, mas notem que a violação cometida durante a guerra só começou a ter grande publicidade quando ocorreu no início dos anos noventa na Europa. Pouco se soube acerca do quarto a meio milhão de mulheres, quase todas Tutsi, violadas em 1994 durante o genocídio no Ruanda, e pouco se sabe sobre os muitos milhares de mulheres violadas durante os contínuos conflitos no Congo.

É mais fácil ignorar o sofrimento dos outros se eles forem vistos como culpados da sua própria situação ou como muito diferentes, de menor valor, inferiores, sub-humanos, estranhos ou de uma outra "raça". Isto permite atribuir pouca ou nenhuma importância ao seu sofrimento. Charles Mills argumenta que o contrato racial implica que o sofrimento dos brancos tem muito mais valor do que o dos não-brancos. Eu concordo, mas acrescentaria que o contrato sexual desempenha um papel igualmente importante no fomento da indiferença. $\mathrm{O}$ argumento de Geras sobre o contrato da indiferença mútua refere-se a calamidades e sofrimento extremos, mas a indiferença faz parte da vida quotidiana. As concepções dominantes de "raça" e de masculinidade e feminilidade cultivam e mantêm a indiferença. A lição de que as meninas e mulheres valem menos do que os meninos e homens, e de que as mulheres "deles" valem menos do que as "nossas" é transmitida de múltiplas maneiras.

A ilustração mais vívida do contrato sexual-racial global é o tráfico sexual e a violência contra as mulheres, incluindo a violação. $O$ tráfico sexual - a procura por parte dos homens dos corpos das mulheres à venda como mercadoria no mercado - aumentou rapidamente desde que escrevi The Sexual Contract. Este comércio tem sido alimentado pelo empobrecimento das mulheres (incluindo na Rússia e nos países do ex-bloco soviético) e pelas guerras das duas últimas décadas. As mulheres emigram para trabalhar nesta indústria e são também enganadas e forçadas a fazê-lo, constituindo um dos produtos de numerosas organizações criminosas bem organizadas. As mulheres e as jovens nos campos de refugiados e em zonas de conflito têm frequentemente de facultar sexo aos seus "protectores" - os membros das forças de manutenção da paz das Nações Unidas e os funcionários de agências de apoio humanitário - em troca de meios de subsistência. 
Os fluxos globais de mulheres dentro da indústria do sexo, à semelhança dos fluxos do tráfico de empregadas domésticas, estão suficientemente bem definidos para figurarem no mapa (ver Seager, 2003).

Entretanto, a violência contra as mulheres continua sem diminuir. Em Novembro de 2005, a Organização Mundial da Saúde publicou um relatório sobre a violência doméstica que mostra como este é um problema global, ocorrendo tanto em países ricos como pobres, facto de que as académicas e activistas feministas há muito têm consciência. Não há nenhum país em que a integridade física das mulheres esteja garantida. A violação é endémica em todo o mundo, cometida pelos homens com quase absoluta impunidade. Por exemplo, a ONU descobriu que quase metade das raparigas dos bairros pobres do Haiti foram violadas ou sujeitas a outro tipo de violência sexual. Um repórter de visita ao Haiti relata que perguntara a um alto funcionário da ONU no país por que razão tão pouco tinha sido feito e por que razão tais actos de violência tinham tido tão pouca divulgação. A resposta foi: "Não pode imaginar a falta de interesse que há no sistema da ONU relativamente a este problema" (Renton, 2008: 25). Nunca se declarou nenhum estado de emergência ou "guerra ao terrorismo" por causa da escala da violência contra as mulheres.

Apesar da indiferença, é agora muito mais fácil ficar a par dos problemas que tenho estado a discutir, que são mais divulgados do que nunca. Dois aspectos encorajadores são o aumento do interesse pelos direitos humanos das mulheres e o surgimento de uma multiplicidade de movimentos de mulheres por todo o mundo que trabalham ao nível das bases para melhorar a posição das mulheres nas suas próprias zonas.

Todavia, é muito mais fácil expor os obstáculos à cidadania plena das mulheres do que dar respostas à questão do que se pode fazer para os ultrapassar. Torna-se extremamente difícil encontrar uma solução enquanto se continuarem a desenvolver políticas de privatização e desregulação, bem como a chamada "guerra ao terrorismo". Esta última fomenta um tipo de mentalidade semelhante à do período colonial: a posição das mulheres cá dentro pode ser sempre favoravelmente comparada à das mulheres dos países que agora são apresentados como refúgio de "terroristas" e num estádio inferior de civilização.

Não tenho uma solução fácil para a forma como se pode fazer um corte decisivo na interacção do contrato de indiferença mútua com o contrato sexual-racial global, mas tenho uma pequena sugestão para o desenvolvimento de políticas que poderiam começar a fazer uma diferença efectiva na cidadania das mulheres. Em 1792, como parte da sua argumentação a favor da igualdade de estatuto de cidadania das mulheres, Mary Wollstonecraft 
defendeu que todas as mulheres, tanto casadas como solteiras, deveriam ser economicamente independentes. A concretização deste objectivo é dificultada pelo facto de que, embora se aceite o direito ao voto hoje em dia, rejeita-se normalmente o direito a um nível de vida decente. A atribuição de um rendimento básico a todos os cidadãos constituiria um passo em direcção a garantir tal direito e um passo em direcção a uma cidadania plena (o Brasil é o único país que produziu legislação sobre o rendimento básico, mas há crescente apoio popular a esta política em todo o mundo).

A ideia do rendimento básico é que cada cidadão receba um pagamento regular, a título individual, inteiramente isento de condições; assim, são irrelevantes o estado civil ou a situação profissional. Uma questão crucial é a do nível que se deve estabelecer para tal rendimento. Eu defendo que esta política só poderá contribuir significativamente para a cidadania se o pagamento for fixado bem acima da linha da pobreza - deveria bastar para manter o que chamei um nível de vida modesto mas decente; deveria possibilitar a participação dos indivíduos na vida das suas sociedades. ${ }^{2}$ Em termos globais, poderia estabelecer-se um nível adequado para cada país.

O rendimento básico disponibilizaria uma série de oportunidades para as mulheres e permitir-lhes-ia, se estiverem dispostas a viver apenas desse rendimento, abandonar relações e empregos degradantes. Em termos mais latos, o rendimento básico daria uma base material de sustento à cidadania para todos e, de forma igualmente importante, constituiria uma afirmação simbólica de que cada indivíduo é importante como membro igual da sociedade e tem o mesmo valor como cidadão. No meu trabalho sobre o rendimento básico, tenho também defendido o seu potencial para resolver algumas questões que são vitais para a melhoria da cidadania das mulheres. Mas esse potencial só se concretizará se o rendimento básico for defendido de determinada maneira: a sua importância para a democratização e para a liberdade das mulheres tem de estar no centro do debate (o que não é o caso actualmente, dado que as discussões académicas se desenvolvem geralmente em torno da justiça social e a produção académica feminista é em grande medida ignorada).

Se a causa do rendimento básico for defendida como deve ser, a discussão das políticas poderia abrir o debate sobre a relação entre o casamento, o emprego e a cidadania, a relação entre o trabalho remunerado e não remunerado e a questão do que conta como "trabalho". Estes assuntos são normalmente periféricos ao debate político convencional, mas são

\footnotetext{
${ }^{2}$ Ver Pateman, 2003 e 2004. Para mais informação sobre o rendimento básico, consultar www. basicincome.org.
} 
fundamentais para a manutenção das estruturas de poder sexual e, portanto, para a cidadania das mulheres. Essas estruturas foram abaladas no decurso do último quartel, mas estão longe de ter ruído; há ainda um longo caminho a percorrer até que as mulheres em todo o mundo alcancem a cidadania plena.

Tradução de
Teresa Tavares

\section{Referências bibliográficas}

Dobson, Roger; Waite, Roger (2007), "Men Opt Out of Housework after Marriage”, Sunday Times, 12 de Agosto.

Ehrenreich, Barbara; Hochschild, Arlie (orgs.) (2002), Global Women: Nannies, Maids, and Sex Workers in the New Economy. New York: Metropolitan Books.

Geras, Norman (1998), The Contract of Mutual Indifference: Political Philosophy After the Holocaust. London/New York: Verso.

Mills, Charles (1997), The Racial Contract. Ithaca, NY: Cornell University Press.

Pateman, Carole (1988), The Sexual Contract. Cambridge: Polity Press and Stanford University Press.

Pateman, Carole (2003), "Freedom and Democratization: Why Basic Income is to be Preferred to Basic Capital,” in Keith Dowding, Jurgen De Wispelaeire e Stuart White (orgs.), The Ethics of Stakeholding. London: Palgrave.

Pateman, Carole (2004), "Democratizing Citizenship: Some Advantages of a Basic Income," Politics and Society, 32(1). Publicado também em E. O. Wright (org.) (2005), Redesigning Distribution. London: Verso.

Pateman, Carole; Mills, Charles (2007), Contract and Domination. Cambridge: Polity Press.

Rawls, John (1971), A Theory of Justice. Cambridge, Mass.: Harvard University Press. Renton, Alex (2008), “The Rape Epidemic”, The Guardian Weekly, 11 de Janeiro.

Seager, Joni (2003), The Penguin Atlas of Women in the World. Ed. rev. New York: Penguin.

Sen, Amartya (1990), “More than 100 Million Women are Missing”, New York Review of Books, 20 de Dezembro, 61-66.

Wollstonecraft, Mary (1993), “A Vindication of the Rights of Woman”, in Janet Todd (org.), The Political Writings of Mary Wollstonecraft. Toronto: University of Toronto Press [1792]. 